\title{
Platelet-rich plasma therapy - future or trend?
}

\author{
Robinder S Dhillon ${ }^{1,2}$, Edward M Schwarz',2, Michael D Maloney 1,2,*
}

\begin{abstract}
Chronic complex musculoskeletal injuries that are slow to heal pose challenges to physicians and researchers alike. Orthobiologics is a relatively newer science that involves application of naturally found materials from biological sources (for example, cell-based therapies), and offers exciting new possibilities to promote and accelerate bone and soft tissue healing. Platelet-rich plasma (PRP) is an orthobiologic that has recently gained popularity as an adjuvant treatment for musculoskeletal injuries. It is a volume of fractionated plasma from the patient's own blood that contains platelet concentrate. The platelets contain alpha granules that are rich in several growth factors, such as platelet-derived growth factor, transforming growth factor- $\beta$, insulin-like growth factor, vascular endothelial growth factor and epidermal growth factor, which play key roles in tissue repair mechanisms. PRP has found application in diverse surgical fields to enhance bone and soft-tissue healing by placing supra-physiological concentrations of autologous platelets at the site of tissue damage. The relative ease of preparation, applicability in the clinical setting, favorable safety profile and possible beneficial outcome make PRP a promising therapeutic approach for future regenerative treatments. However, there is a large knowledge gap in our understanding of PRPs mechanism of action, which has raised skepticism regarding its potential efficacy and use. Thus, the aim of this review is to describe the various factors proposed to contribute to the biological activity of PRP, and the published pre-clinical and clinical evidence to support it. Additionally, we describe the current techniques and technology for PRP preparation, and review the present shortcomings of this therapy that will need to be overcome if it is to gain broad acceptance.
\end{abstract}

*Correspondence: mike_maloney@urmc.rochester.edu

2Department of Orthopaedics, University of Rochester, Rochester, NY 14642, USA Full list of author information is available at the end of the article

\section{Introduction}

Platelet-rich plasma (PRP) is defined as a portion of the plasma fraction of autologous blood having a platelet concentration above baseline [1]. It is an emerging treatment in the modern health sector known as 'orthobiologics.' The goal of this discipline is to enhance the body's innate ability to repair and regenerate. PRP therapy has lately gained a lot of attention as a safe, nonsurgical, biological treatment of osteoarthritis and musculoskeletal repair [2]. The global market for PRP was valued at $\$ 45$ million in 2009 , and is projected to be worth more than $\$ 120$ million by 2016 [3]. That being said, presently there is a lack of data available to truly confirm that PRP works as postulated. Future large randomized controlled trials (RCTs) are needed to assess its efficacy. Thus, PRP should be used with great caution at this time.

\section{Clinical relevance - the 'need'}

Musculoskeletal conditions have an enormous and growing impact worldwide [4]. The World Health Organization has acknowledged that musculoskeletal injuries affect hundreds of millions of people worldwide and are the most common cause of severe long-term pain and physical disability [5].

Soft tissue injuries that include ligament and tendons represent up to $45 \%$ of all musculoskeletal injuries [6,7]. Chronic and degenerative musculoskeletal conditions can be challenging to treat and can have a protracted course compromising an otherwise active lifestyle. Many of these patients with sports- or overuse-related injuries might require a surgical intervention and protracted rehabilitation and yet have unclear outcomes. Additionally, there is still a dearth of treatments that could effectively enhance repair in the face of these chronic conditions. It is in this setting that pre-clinical studies and case reports suggesting improvement of osteoarthritis symptoms with PRP treatment have generated interest in its application for articular cartilage repair. If proven effective, this would constitute a breakthrough non-operative treatment option for osteoarthritis.

\section{Platelet physiology and function}

A typical blood specimen comprises $93 \%$ red blood cells, $6 \%$ platelets, and $1 \%$ white blood cells [8]. Platelets were 
first seen in the blood by French physician Alfred Donné in 1842 [9]. These are small discoid cells with a life span of about 7 to 10 days. Following injury that causes bleeding, platelets are activated and aggregate together to release their granules containing growth factors that stimulate the inflammatory cascade and healing process. Platelets are responsible for hemostasis, construction of new connective tissue and revascularization and most of the research over the past century has been focused on this primary function [10]. Only in the past two decades have we learned that platelet activation in the body releases healing proteins called growth factors [11]. There are numerous growth factors with diverse functions, but cumulatively they may accelerate tissue and wound healing [12].

The ideology behind PRP treatment is the reversal of the red blood cell:platelet ratio by decreasing red blood cells to 5\% (which are less useful in the healing process) and more importantly concentrating platelets containing a powerful concoction of growth factors to $94 \%$. A normal platelet count in a healthy individual is between 150,000 and 450,000 cells per microliter of blood. Platelet concentrations of less than $1,000 \times 10^{6} / \mathrm{ml}$ were not reliable for enhancing wound healing [1], and most studies have suggested that tissue reparative efficacy with PRP can be expected with a minimum increase of five times the normal concentration of platelets (approximately 1 million platelets/ $\mu$ l) [13], whereas much higher concentrations did not show further enhancement of wound healing. The ideal concentration remains to be defined. The broad variability in platelet concentrating equipment and techniques used [14] in different studies may alter platelet degranulation characteristics that could affect clinical outcomes [15-17], making interpretation of the results challenging.

\section{Growth factors in platelet-rich plasma}

The notable components of PRP presented in Table 1 include transforming growth factor (TGF)- $\beta$, plateletderived growth factors (PDGF-AB and PDGF-BB), insulin-like growth factor (IGF), vascular endothelial growth factors (VEGFs), epidermal growth factor (EGFs) and fibroblast growth factor (FGF)-2 [15,18,19]. TGF- $\beta 1$ and PDGF stimulate proliferation of mesenchymal cells. TGF- $\beta 1$ also stimulates extracellular matrix production, including collagen. Principally, these factors stabilize the damaged tissue during initial stages of tissue repair, and direct the local mesenchymal and epithelial cells to migrate, divide, and increase collagen and matrix synthesis, ultimately leading to fibrous connective tissue and scar formation [20]. VEGF and FGF-2 are important for stimulating new blood vessel formation to bring nutrients and progenitor cells to the injury site; however, additional factors are also required for neo-vascularization. PRP is postulated to improve the early healing of tendon defects by over-expression of IGF-1 [21]. The 70 amino acid polypeptide hormone IGF is a normal component of the plasma and is transported by IGF-binding proteins [2224]. IGF-1 storage in platelets is unclear, with few proteomic studies reporting it to be absent and most literature detecting IGF-1 in platelets $[19,25,26]$; however, most studies have detected IGF-1 in PRP [27-29]. For PRP's role in multiple healing pathways, it deserves due consideration as an adjunctive therapy for specific applications.

\section{Clinical application for platelet-rich plasma}

Autologous PRP injections were reportedly first used in 1987 in an open heart surgery [30]. Over 20 years ago, PRP was used in the dental field for promoting accelerated wound healing in cancer patients following jaw reconstruction. Physicians have used PRP to aid bone healing after spinal injury and soft tissue recovery following plastic surgery. PRP therapy gained broad popularity in early 2009, when it was reported that two of the Pittsburgh Steelers received PRP for their ankle injuries before their triumph at the Super Bowl. Due to the media attention, PRP became an accepted though unproven treatment for sports-related injuries [31]. Currently, PRP injections are being used in various applications, including orthopaedics, cardiovascular surgery, cosmetics, facio-maxillary surgery and urology [10]. As a result, multiple studies are now underway to understand PRP's mechanism of action, refine the treatment, and formally demonstrate efficacy in placebocontrolled trials.

\section{Platelet-rich plasma treatment - what does it entail?}

The simplicity of PRP application is defined by three steps (Figure 1). For most orthopedic use, which currently happens to be in an outpatient setting, the physician harvests the venous blood and transfers it to the centrifuge. Once the blood is in the centrifuge, processing usually takes between 5 and 20 minutes, and a sterile barrier may be necessary, depending on automation and centrifuge processing protocols. The current recommendations state that the platelet concentration should be raised between four and six times above the baseline concentration. After the centrifuge processes, the physician extracts PRP according to device instructions. The platelets collected in PRP are often activated by the addition of thrombin and calcium chloride, which induce the release of these factors from the alpha granules. With wider acceptance of PRP treatment, its application is selectively being adapted for use in the operating room while surgery is in progress.

Research is ongoing to determine the best concentration, preparation and timing of the injections. We know 
Table 1. Summary of growth factors contained in platelet-rich plasma $[64,77,78]$

\begin{tabular}{|c|c|}
\hline Growth factor & Function \\
\hline \multirow[t]{6}{*}{ Transforming growth factor- $\beta$ (TGF- $\beta$ ) } & Stimulates undifferentiated mesenchymal cell proliferation \\
\hline & Regulates endothelial, fibroblastic, and osteoblastic mitogenesis \\
\hline & Regulates collagen synthesis and collagenase secretion \\
\hline & Regulates mitogenic effects of other growth factors \\
\hline & Stimulates endothelial chemotaxis and angiogenesis \\
\hline & Inhibits macrophage and lymphocyte proliferation \\
\hline \multirow[t]{2}{*}{ Fibroblast growth factor (FGF) } & Promotes growth and differentiation of chondrocytes and osteoblasts \\
\hline & Mitogenetic for mesenchymal cells, chondrocytes, and osteoblasts \\
\hline \multirow[t]{4}{*}{ Platelet-derived growth factor a and b (PDGF) } & Mitogenetic for mesenchymal cells and osteoblasts \\
\hline & Stimulates chemotaxis and mitogenesis in fibroblast, glial, or smooth muscle cells \\
\hline & Regulates collagenase secretion and collagen synthesis \\
\hline & Stimulates macrophage and neutrophil chemotaxis \\
\hline \multirow[t]{3}{*}{ Epidermal growth factor (EGF) } & Stimulates endothelial chemotaxis or angiogenesis \\
\hline & Regulates collagenase secretion \\
\hline & Stimulates epithelial or mesenchymal mitogenesis \\
\hline \multirow[t]{2}{*}{ Vascular endothelial growth factor (VEGF) } & Increases angiogenesis and vessel permeability \\
\hline & Stimulates mitogenesis for endothelial cells \\
\hline \multirow[t]{3}{*}{ Connective tissue growth factor (CTGF) } & Promotes angiogenesis \\
\hline & Cartilage regeneration \\
\hline & Fibrosis and platelet adhesion \\
\hline \multirow[t]{2}{*}{ Insulin like growth factor (ILGF 1 and 2) } & Chemotactic for fibroblasts and stimulates protein synthesis \\
\hline & Enhances bone formation \\
\hline \multirow[t]{2}{*}{ Platelet factor 4 (PF-4) } & Stimulate the initial influx of neutrophils into wounds \\
\hline & Chemo-attractant for fibroblasts \\
\hline \multirow[t]{2}{*}{ Interleukin 8 (IL-8) } & Pro-inflammatory mediator \\
\hline & Recruitment of inflammatory cells \\
\hline \multirow[t]{2}{*}{ Keratinocyte growth factor (KGF) } & Promote endothelial cell growth, migration, adhesion and survival \\
\hline & Angiogenesis \\
\hline
\end{tabular}

of several techniques for PRP preparation (Figure 2), with multiple commercially available products (Table 2 ); however, their application has been confusing because each technique leads to a different product with potentially dissimilar biology and unknown relative efficacy.

\section{Variations in platelet-rich plasma preparations}

The importance of having such a classification is to better understand the relative success or failure of different PRP preparations. Additionally, this can establish an objective approach for future development and research.

Although the evidence is anecdotal, platelet-leukocyterich plasma (PLRP) deserves a notable mention as a novel concept. PLRP enriched in growth factors and antimicrobial proteins has been used to address infection concerns in healing injuries associated with soft tissue defects. Cieslik-Bielecka and colleagues [32] were the first to report the application of PLRP in an infected high-energy soft tissue injury and indicated that the volume and concentration of platelets and leukocytes were adequate to induce the healing process despite concurrent infection.

\section{Proposed mechanisms of action}

Most of the published literature on the efficacy of PRP in treating orthopedic conditions, ranging from acute rotator cuff tears to chronic achilles tendinitis, inherently lack accurate reporting of the specific formulation used. The variability in the composition and preparation methods poses a predicament in making true comparisons between different studies and their relative 


\section{Blood Collection
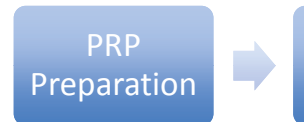 \\ Local \\ Injection}

Figure 1. The three-step process of platelet-rich plasma (PRP) treatment.

effectiveness. Principally, application of an autologous plasma rich in growth factors is considered to be beneficial in restoring connective tissues because of the slow delivery of growth factors from harvested platelets that have been activated by endogenous thrombin promoted by the addition of calcium chloride [33]. Admittedly, the precise mechanisms of action of PRP are poorly understood.

\section{Basic science of platelet-rich plasma therapy In vitro studies \\ Bone formation}

PRP and its soluble fraction stimulate the osteoblastic differentiation of myoblasts and osteoblastic cells in threedimensional cultures in the presence of bone morphogenetic protein (BMP)-2, BMP-4, BMP-6 or BMP-7 [34]. Moreover, heparin-binding fractions obtained from serum also stimulated osteoblastic differentiation in the presence of BMP-4. These results suggested that platelets contain not only growth factors for proliferation but also novel potentiator(s) for BMP-dependent osteoblastic differentiation.

\section{Osteoarthritis}

Platelet released growth factors (PRGFs) regulate endogenous hyaluronic acid (HA) synthesis, thereby protecting the cartilage and lubricating the joint [35]. PRGF enhances the secretion of HA and induces hepatocyte growth factor (HGF) production by synovial fibroblasts isolated from arthritic patients [36]. Platelets preincubated in an acidic environment ( $\mathrm{pH}$ 5.0) induced the highest degree of fibroblast proliferation and the concentration of PDGF in the different treated lysates [37]. Intra-articular administration of PDGF might be beneficial in restoring HA concentration and switching angiogenesis to a more balanced status but does not halt the effects of IL- $1 \beta$ on synovial cells.

\section{Tendon healing}

In 1994, Packer and colleagues [38] described an in vitro model to study fibroblast activity during tendon healing. Later, Bernard-Beaubois and colleagues [39] were the first to culture and characterize the rabbit tenocytes in vitro, and Schulze-Tanzil and colleagues [40] established a three-dimensional high-density culture system for cultivation of human tenocytes for tissue engineering.

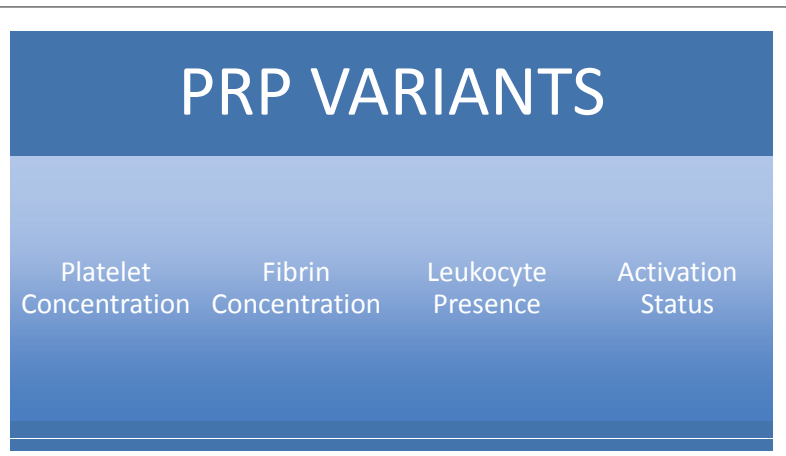

Figure 2. Bases for potential classification systems for plateletrich plasma (PRP).

An in vitro study suggested that administering autologous platelet-rich clots might be beneficial in the treatment of tendon injuries by inducing cell proliferation and promoting the synthesis of angiogenic factors during the healing process [41]. Cultured tendon cells synthesize VEGF and HGF in the presence of growth factors from PRP clots, with the amounts synthesized being significantly higher with supernatants from platelet-rich clots than supernatants from a platelet-poor clot. Also notable was that the mitogenic activity of the supernatants was not decreased by the thrombin inhibitor hirudin. In human tenocyte cultures, not only plateletrich clot relesate, but also platelet-poor clot relesate, stimulated cell proliferation and total collagen production. The former, but not the latter, slightly increases the expression of matrix-degrading enzymes (matrix metalloproteinases (MMPs) 1, 3 and 13) and endogenous growth factors (TGF- $\beta$ and VEGF-a) [42].

\section{Animal studies}

\section{Distraction osteogenesis}

In the rabbit bone defect/lengthening model, local injection of PRP enhanced bone consolidation during the consolidation phase; however, in the early stage of distraction osteogenesis, the combined use of decalcified bone matrix along with PRP did not reveal any additional benefit [43].

\section{Muscle healing}

Muscle healing is an intricate and dynamic process aimed at restoration of anatomic continuity and function of the injured muscle [18]. Local delivery of PRP has been found to shorten the recovery time after a muscle strain injury in a small-animal model [44].

\section{Osteochondral defect repair}

Sun and colleagues [45] in their rabbit model of osteochondral defect found improved healing as assessed by macroscopic examination, micro-computed tomography, 
Table 2. Classification of different platelet concentrates into four broad categories depending on leukocyte and fibrin content alone [14]

\begin{tabular}{ll}
\hline Category & Example \\
\hline Pure platelet rich plasma & $\begin{array}{l}\text { Cell separator PRP, Vivostat PRF or } \\
\text { Anitua's PRGF }\end{array}$ \\
Leukocyte and platelet rich plasma & $\begin{array}{l}\text { Curasan, Regen, Plateltex, } \\
\text { SmartPReP, PCCS, Magellan or } \\
\text { GPS PRP }\end{array}$ \\
Pure platelet rich fibrin & Fibrinet \\
Leukocyte and platelet rich fibrin & Choukroun's PRF \\
\hline
\end{tabular}

GPS, gravitational platelet separation; PCCS, platelet concentrate collection system; PRF, platelet rich fibrin; PRGF, platelet released growth factor; PRP, platelet-rich plasma.

and histological evaluation at 4 and 12 weeks with PRP in poly-lactic-glycolic acid.

\section{Tendon healing}

In a rabbit patellar tendon defect model, a single application of PRP was found to improve tendon defect healing by over-expression of IGF-1 [21]. Another study with equine tendons cultured in 100\% PRP demonstrated enhanced gene expression of the matrix molecules collagen type I (COL1A1), collagen type III (COL3A1), cartilage oligomeric matrix protein (COMP) without an associated increase in the catabolic molecules MMP-3 and MMP-13 [46]. Some studies implicate PRP in enhancing neovascularization that further accelerates the healing process and promotes better histological quality scar tissue formation [47]. Lyras and colleagues [48] found a significant improvement in the mechanical properties of the regenerated tendon in the PRP-treated group at 14 days, returning to baseline at 28 days, concluding that PRP has a strong effect in the early phases of tendon healing.

\section{Human clinical studies - applications in different pathological conditions}

The use of platelet rich plasma is still a relatively new treatment for orthopedic patients, although physicians are increasingly using PRP as an alternative to medication and surgery. Although much of the literature has a low evidence level - that is, case-control studies, case series and anecdotal case reports - there are a handful of RCTs on this subject. Pooled results from six randomized trials from different clinical applications of PRP in a recent meta-analysis [49] found no significant benefit up to 24 months with the use of PRP. The observed trend towards benefit with PRP use still remains questionable.

\section{Articular cartilage repair}

Sanchez and colleagues [33] describe a case report where autologous plasma rich in growth factors was injected into the area between the defect and the fixed fragment after the arthroscopic fixation of a large $(>2 \mathrm{~cm})$ loose chondral body from the medial femoral condyle in the knee of an adolescent soccer player. Despite the poor prognosis, complete articular cartilage healing was reported to be accelerated and functional outcome was remarkable, allowing a quick return to symptom-free athletic activity.

\section{Achilles tendon repair}

A case-control (level 3 evidence) study comparing open suture repair in conjunction with a preparation rich in growth factors (PRGF) in six athletes and retrospective comparison with six matched athletes who had a conventional surgical procedure for a complete Achilles tendon tear reported that athletes receiving PRGF recovered their range of motion earlier, showed no wound complication, and took less time to resume gentle running and training activities [50]. The cross-sectional area of the PRGF-treated tendons increased less, and TGF- $\beta 1$, PDGF- $\alpha \beta$, VEGF, EGF and HGF significantly correlated with the number of platelets, suggesting that operative management of tendons combined with the application of autologous PRGF promoted enhanced healing and functional recovery.

On the contrary, a RCT of 30 patients with surgical repair of Achilles tendon reported no additional benefit of PRP over standard treatment [51]. The Achilles Tendon Total Rupture Score was lower in the PRP group, possibly suggesting a detrimental effect. A variation in elasticity modulus was observed, although it was unclear how early biomechanics could be connected to late clinical results. In another independent RCT of patients with chronic Achilles tendinopathy, a PRP injection was no better in improving pain and activity compared to saline injection [52].

\section{Anterior cruciate ligament repair}

A human study examined the effects of local platelet gel application on graft healing in bone tunnels and the ligamentization process after anterior cruciate ligament (ACL) reconstruction [53]. Locally applied platelet gel enhanced early revascularization of the graft in the osteoligamentous interface zone after ACL reconstruction. After 4 to 6 weeks, the platelet gel-treated group demonstrated a significantly higher level of vascularization in the osteoligamentous interface, with no evidence of revascularization in the intra-articular part of the graft in either group.

Vogrin and colleagues [54] in their study evaluating the effects of local application of platelet-leukocyte gel on knee stability after ACL reconstruction surgery reported significantly better anteroposterior knee stability at 6 months with PRP treatment. 


\section{Arthroplasty}

A retrospective case control study has described the effect of autologous platelet gel applied to exposed tissues, synovium and the lining of the wound at closure following total knee arthroplasty [55]. Interestingly, the patients receiving platelet gel during surgery had less postoperative blood loss as measured by differences in preoperative and postoperative hemoglobin on day 3, lesser narcotic requirement and a higher range of motion prior to discharge than their control counterparts. Researchers concluded that the application of autologous platelet gel might lead to improved hemostasis, better pain control and a shortened hospital stay.

Everts and colleagues [56] obtained similar results in their study, where autologous platelet gel and fibrin sealant application during unilateral total knee arthroplasty was found to help reduce the peri-operative incidence of blood transfusions.

\section{Epicondylitis}

A Dutch RCT comparing the effectiveness of leukocyteenriched PRP to standard corticosteroid treatment for lateral epicondylitis found the former reduced visual analog scale pain scores and Disabilities of the Arm, Shoulder and Hand (DASH) outcome scores by 25\% [57]. When baseline visual analog scale and DASH scores were compared with the scores at 2-year follow-up, both groups significantly improved across time. However, the DASH scores of the corticosteroid group returned to baseline levels, while those of the PRP group remained significantly improved. Furthermore, there were no adverse effects related to the use of PRP in 51 patients. Another independent study found a single platelet-rich plasma injection improved pain and function scores in 29 patients who failed to improve with 6 months of corticosteroid treatment [58].

\section{Osteoarthritis}

A study of 261 patients with symptomatic osteoarthritis of the knee, following intra-articular infiltration of PRGF, reported improvement in the function and quality of life measured by osteoarthritis-specific and general clinical assessment instruments at 6-month follow-up [59]. These findings suggest PRGF is a potential therapy for osteoarthritis. Filardo and colleagues [60] in a study of 91 patients observed that treatment with PRP injections reduced pain and improved knee function and quality of life with short-term efficacy; the greatest effect was observed at 12 months but diminished by 24 months.

\section{Rotator cuff repair}

Rendelli and colleagues [61] in their prospective, randomized, controlled, double blind study of 53 patients with complete rotator cuff tear observed a lower pain score at 3, 7, 14 and 30 days after surgery with the local application of autologous PRP. Additionally, the Simple Shoulder Test, University of California Los Angeles (UCLA), Constant scores and strength in external rotation as measured by a dynamometer were significantly higher in the treatment group than the control group at 3 months after surgery. However, no long-term noticeable differences were noted after 6 months. Followup magnetic resonance imaging showed no significant difference in the healing rates of the rotator cuff tear in both groups. The long-term results of subgroups of grade 1 and 2 tears suggest that PRP positively affected cuff rotator healing. On the contrary, Castricini and colleagues [62] in their RCT did not find the use of autologous platelet-rich fibrin matrix beneficial for augmentation of a double-row repair of small or medium rotator cuff tears. These results, however, are applicable only for small and medium rotator cuff tears, with an undetermined possibility of benefit of platelet-rich fibrin matrix for large and massive rotator cuff tears.

\section{Sub-acromial decompression}

A study of 40 patients evaluating the effect of plateletleukocyte gel produced from PLRP on the postoperative recovery of patients undergoing open sub-acromial decompression observed faster recovery, earlier return to daily activities and decreased pain medication requirement in the platelet-leukocyte gel-treated group [63].

\section{Safety profile}

Since PRP is prepared from autologous blood, theoretically there are minimal risks for disease transmission, immunogenic reactions or cancer [64]. Based on the pioneering and long-term clinical experience of the oralmaxillary field with PRP, and thousands of patients being treated so far, the use of PRP is considered to be safe $[65,66]$. In the musculoskeletal field, although no longterm outcome studies with PRP exist, a large number of patients have been treated worldwide. Wang-Saegusa and colleagues [59] in their study of over 800 patients reported no adverse effects following injection of plasma rich in growth factors (PRGF) into the knee joint at 6 months.

Adverse effects are rare but, as with any injection, there is always a small risk of injection site morbidity, infection or injury to nerves or blood vessels. Scar tissue formation and calcification at the injection site have been reported [10]. Hypersensitivity to the bovine thrombin used for activation was concerning and is therefore avoided in modern techniques. Rarely, development of antibodies against clotting factors $\mathrm{V}$ and IX leading to lifethreatening coagulopathies have been reported [67-69]. To date, there is no compelling evidence of any systemic effects of a local PRP injection. Some probable arguments 
for these considerations include the limited need of PRP injections in clinics (as PRP is not chronically administered) and the short in vivo half-lives and local bioavailability of growth factors produced by PRP. In our review of literature we did not come across RCTs that have comprehensively evaluated the safety of PRP treatment.

\section{Practical aspects and issues}

Physicians thinking about using PRP in their practices should consider the time commitment it takes to learn and employ the technique, insurance coverage, informed consent and sporting regulations.

Role of insurance companies - billing and reimbursement A logistical problem with providing PRP injections is that most insurance plans do not reimburse for this procedure. The cost of single treatment ranges from $\$ 200$ to $\$ 500$. The Current Procedural Terminology code for PRP injection, which was implemented 1 July 2010, is 0232T (injection(s), platelet-rich plasma, any tissue, including image guidance, harvesting, and preparation when performed). This is a temporary code used for emerging technologies, services, and procedures that allows data collection to be used to document widespread use for Food and Drug Administration approval. This code also includes imaging guidance, harvesting, and preparation; therefore, these aspects of the procedure cannot be billed separately. The placement/injection of the cells into the operative site is an inclusive component of the operative procedure performed and not separately reported. Category III code $0232 \mathrm{~T}$ can only be reported if the PRP injection is performed on a nonsurgical site or when performed unrelated to the surgical site.

\section{Anti-doping regulations and platelet-rich plasma}

The World Anti-Doping Agency (WADA) is an international independent agency that regulates dopingfree sport by enforcing the Anti-Doping Code. WADA monitors the current literature, conducts comprehensive consultations and, upon agreement by expert panels, releases an annual list of prohibited substances. PRP, after being mentioned in its list of prohibited items for the first time in 2010 [70], was subsequently deleted from the 2011 Prohibited List [71]. Initially, only intramuscular PRP injections were prohibited, whereas all other routes of administration, such as intra-articular or intra- or peri-tendinous, were permitted and only required a declaration of use. This restriction was due to the concern of the WADA List Expert Group that growth factors contained in PRP may stimulate muscle satellite cells and increase muscle size and strength beyond normal healing. Specific purified or recombinant growth factors (for example, IGF-1, VEGF, PDGF) are explicitly prohibited except when part of platelet-derived preparations from the centrifugation of autologous whole blood.

The different PRP formulations and treatments existing nowadays have not been found to increase muscle growth beyond return to a normal physiological state. Some animal studies do show faster muscle regeneration and recovery to full function following experimentally induced injury, but no enhancement of performance beyond normal has been reported $[6,72,73]$. It has now generally been agreed by the sporting regulation bodies that the use of PRP injections for therapeutic purposes only does not violate the spirit of sport. Hence, PRP use is currently permissible by all routes of administration. WADA continues to review PRP usage in the light of new scientific information as it becomes available.

\section{Limitations}

The composition of PRP varies from patient to patient and may also vary with the device used to prepare it, the time and method of storage until used and whether it interacts with other biologics or materials. Due to these inherent inconsistencies, the current use of PRP in orthopedics is patient-driven and based on anecdotal reports of its use in elite athletes. Platelet rich plasma may enhance soft-tissue repair, especially for tendons, though it may inhibit bone formation [74]. Some physicians use PRP as a way to provide and/or promote growth factors and cytokines during tissue repair. PRP can lead to fibrous connective tissue and scar formation. Additionally, PRP is not osteoinductive. This field is still blurred by controversial results from different studies, and a definite direction remains elusive [75]. The American Academy of Orthopaedic Surgeons, at their 2011 PRP Forum, concluded that 'PRP is an option that yet remains unproven' [76].

\section{Conclusion}

PRP was a major initial step that led researchers to consider bone marrow aspirates and stem cells in the growing field of 'orthobiologics'. Available data suggest that PRP may be helpful in enhancing soft-tissue repair, particularly for tendon and wound healing. The clinical application of PRP in arthritis and bone repair remains controversial. PRP is most helpful in chronic tendinopathies, such as tennis elbow and patellar tendonitis, as well as certain revision surgeries with compromised healing milieu.

The role of PRP in the directed stimulation of musculoskeletal and mesenchymal stem cells is being widely investigated and shows promise as a short-term use agent that may assist in the simultaneous healing of several musculoskeletal tissues after trauma or elective surgery. PRP is not uniformly successful as an adjuvant to bone grafting procedures. The potential role of PRP in 
healing musculoskeletal injuries, especially in elite athletes, is an exciting frontier that may eventually lead to superior therapies, but a healthy amount of caution should be exercised until clinical evidence is established. Continued research is required to optimize its preparation and use during surgery, to evaluate relative effectiveness of various techniques and to determine the best ways to use it to improve healing.

This article is part of the series on Cutting edge topics and advances in orthopaedic research, edited by Edward Schwarz and Jay Lieberman. Other articles in this series can be found at http://arthritis-research.com/series/orthopaedics

\section{Abbreviations}

$A C L$, anterior cruciate ligament; BMP, bone morphogenetic protein; DASH, Disabilities of the Arm, Shoulder and Hand; EGF, epidermal growth factor; FGF, fibroblast growth factor; HA, hyaluronic acid; HGF, hepatocyte growth factor; IGF, insulin-like growth factor; IL, interleukin; MMP, matrix metalloproteinase; PDGF, platelet-derived growth factor; PLRP, platelet-leukocyte-rich plasma; PRGF, platelet released growth factor; PRP, platelet-rich plasma; RCT, randomized controlled trial; TGF, transforming growth factor; VEGF, vascular endothelial growth factor; WADA, World Anti-Doping Association.

\section{Competing interests}

The authors declare that they have no competing interests. No funding was received for preparation of this manuscript.

\section{Acknowledgements}

RS Dhillon and EM Schwarz are supported by the grants from the National Institute of Health (DE019902, AR054041, AR056702 and AR061307).

\section{Author details}

'The Center for Musculoskeletal Research, University of Rochester, Rochester, NY 14642, USA. ${ }^{2}$ Department of Orthopaedics, University of Rochester, Rochester, NY 14642, USA.

Published: 8 August 2012

\section{References}

1. Marx RE: Platelet-rich plasma (PRP): what is PRP and what is not PRP? Implant Dent 2001, 10:225-228.

2. Schwarz A: A Promising Treatment for Athletes, in Blood. The New York Times 2009 [http://www.nytimes.com/2009/02/17/sports/17blood.html]

3. Platelet Rich Plasma: a Market Snapshot [http://www.docstoc.com/ docs/47503668/Platelet-Rich-Plasma-A-Market-Snapshot]

4. March L, Woolf AD: The global burden of musculoskeletal conditions - why is it important? Best Pract Res Clin Rheumatol 2010, 24:721.

5. Woolf AD, Pfleger B: Burden of major musculoskeletal conditions. Bull World Health Organ 2003, 81:646-656.

6. Banfi G, Corsi MM, Volpi P: Could platelet rich plasma have effects on systemic circulating growth factors and cytokine release in orthopaedic applications? Br J Sports Med 2006, 40:816.

7. Praemer AF: Musculoskeletal Conditions in the United States. 2nd edition. Rosemont: American Academy of Orthopaedic Surgeons; 1999.

8. Marx RE, Garg AK: Dental and Craniofacial Applications of Platelet-Rich Plasma. Carol Stream: Quintessence Publishing Co., Inc.; 2005.

9. Academy of Sciences, Paris: M. Donné on the Blood Globules. Prov Med Surg J (1840) 1842, 3:498-499.

10. Sampson S, Gerhardt M, Mandelbaum B: Platelet rich plasma injection grafts for musculoskeletal injuries: a review. Curr Rev Musculoskelet Med 2008, 1:165-174.

11. Werner $S$, Grose R: Regulation of wound healing by growth factors and cytokines. Physiol Rev 2003, 83:835-870.

12. Anitua E, Sánchez M, Nurden AT, Nurden P, Orive G, Andía I: New insights into and novel applications for platelet-rich fibrin therapies. Trends Biotechnol 2006, 24:227-234.
13. Marx RE: Platelet-rich plasma: evidence to support its use. J Oral Maxillofac Surg 2004, 62:489-496.

14. Dohan Ehrenfest DM, Rasmusson L, Albrektsson T: Classification of platelet concentrates: from pure platelet-rich plasma (P-PRP) to leucocyte- and platelet-rich fibrin (L-PRF). Trends Biotechnol 2009, 27:158-167.

15. Yu W, Wang J, Yin J: Platelet-rich plasma: a promising product for treatment of peripheral nerve regeneration after nerve injury. Int J Neurosci 2011 121:176-180.

16. Weibrich G, Kleis WK, Hafner G, Hitzler WE, Wagner W: Comparison of platelet, leukocyte, and growth factor levels in point-of-care plateletenriched plasma, prepared using a modified Curasan kit, with preparations received from a local blood bank. Clin Oral Implants Res 2003, 14:357-162.

17. Gonshor A: Technique for producing platelet-rich plasma and platelet concentrate: background and process. Int J Periodontics Restorative Dent 2002, 22:547-557.

18. Borrione P, Gianfrancesco AD, Pereira MT, Pigozzi F: Platelet-rich plasma in muscle healing. Am J Phys Med Rehabil 2010, 89:854-861.

19. Christgau M, Moder D, Hiller KA, Dada A, Schmitz G, Schmalz G: Growth factors and cytokines in autologous platelet concentrate and their correlation to periodontal regeneration outcomes. J Clin Periodontol 2006, 33:837-845.

20. Sanchez AR, Sheridan PJ, Kupp LI: Is platelet-rich plasma the perfect enhancement factor? A current review. Int J Oral Maxillofac Implants 2003, 18:93-103.

21. Lyras DN, Kazakos K, Agrogiannis G, Verettas D, Kokka A, Kiziridis G, Chronopoulos E, Tryfonidis M: Experimental study of tendon healing early phase: is IGF-1 expression influenced by platelet rich plasma gel? Orthop Traumatol Surg Res 2010, 96:381-387.

22. Zapf J, Waldvogel M, Froesch ER: Binding of nonsuppressible insulinlike activity to human serum. Evidence for a carrier protein. Arch Biochem Biophys 1975, 168:638-645.

23. Rinderknecht $E$, Humbel RE: The amino acid sequence of human insulinlike growth factor I and its structural homology with proinsulin. J Biol Chem 1978, 253:2769-2776.

24. Froesch ER, Schmid C, Schwander J, Zapf J: Actions of insulin-like growth factors. Annu Rev Physiol 1985, 47:443-467.

25. Hwang DL, Latus $L$, Lev-Ran A: Effects of platelet-contained growth factors (PDGF, EGF, IGF-I, and TGF-beta) on DNA synthesis in porcine aortic smooth muscle cells in culture. Exp Cell Res 1992, 200:358-360.

26. Spencer EM, Tokunaga A, Hunt TK: Insulin-like growth factor binding protein-3 is present in the alpha-granules of platelets. Endocrinology 1993, 132:996-1001.

27. Weibrich G, Kleis WK, Hafner G: Growth factor levels in the platelet-rich plasma produced by 2 different methods: curasan-type PRP kit versus PCCS PRP system. Int J Oral Maxillofac Implants 2002, 17:184-190.

28. Frechette JP, Martineau I, Gagnon G: Platelet-rich plasmas: growth factor content and roles in wound healing. J Dent Res 2005, 84:434-439.

29. Schmidmaier G, Herrmann S, Green J, Weber T, Scharfenberger A, Haas NP, Wildemann B: Quantitative assessment of growth factors in reaming aspirate, iliac crest, and platelet preparation. Bone 2006, 39:1156-1163.

30. Ferrari M, Zia S, Valbonesi M, Henriquet F, Venere G, Spagnolo S, Grasso MA, Panzani l: A new technique for hemodilution, preparation of autologous platelet-rich plasma and intraoperative blood salvage in cardiac surgery. Int J Artif Organs 1987, 10:47-50.

31. Storrs C: Is Platelet-Rich Plasma an Effective Healing Therapy? Scientific American 2009 [http://www.scientificamerican.com/article. cfm?id=platelet-rich-plasma-therapy-dennis-cardone-sports-medicineinjury\&page $=2]$

32. Cieslik-Bielecka A, Bielecki T, GazdzikTS, Arendt J, Król W, Szczepanski T: Autologous platelets and leukocytes can improve healing of infected high-energy soft tissue injury. Transfus Apher Sci 2009, 41:9-12.

33. Sánchez M, Azofra J, Anitua E, Andía I, Padilla S, Santisteban J, Mujika I: Plasma rich in growth factors to treat an articular cartilage avulsion: a case report. Med Sci Sports Exerc 2003, 35:1648-1652.

34. Tomoyasu A, Higashio K, Kanomata K, Goto M, Kodaira K, Serizawa H, Suda T, Nakamura A, Nojima J, Fukuda T, Katagiri T: Platelet-rich plasma stimulates osteoblastic differentiation in the presence of BMPs. Biochem Biophys Res Commun 2007, 361:62-67.

35. Goldring SR, Goldring MB: The role of cytokines in cartilage matrix degeneration in osteoarthritis. Clin Orthop Relat Res 2004, 427 
(Suppl):S27-36.

36. Anitua E, Sánchez M, Nurden AT, Zalduendo MM, de la Fuente M, Azofra J, Andía I: Platelet-released growth factors enhance the secretion of hyaluronic acid and induce hepatocyte growth factor production by synovial fibroblasts from arthritic patients. Rheumatology (Oxford) 2007, 46:1769-1772.

37. Liu Y, Kalén A, Risto O, Wahlström O: Fibroblast proliferation due to exposure to a platelet concentrate in vitro is $\mathrm{pH}$ dependent. Wound Repair Regen 2002, 10:336-340.

38. Packer DL, Dombi GW, Yu PY, Zidel P, Sullivan WG: An in vitro model of fibroblast activity and adhesion formation during flexor tendon healing. J Hand Surg Am 1994, 19:769-776.

39. Bernard-Beaubois K, Hecquet C, Houcine O, Hayem G, Adolphe M: Culture and characterization of juvenile rabbit tenocytes. Cell Biol Toxicol 1997, 13:103-113.

40. Schulze-Tanzil G, Mobasheri A, Clegg PD, Sendzik J, John T, Shakibaei M: Cultivation of human tenocytes in high-density culture. Histochem Cell Biol 2004, 122:219-228

41. Anitua E, Andía I, Sanchez M, Azofra J, del Mar Zalduendo M, de la Fuente M, Nurden P, Nurden A: Autologous preparations rich in growth factors promote proliferation and induce VEGF and HGF production by human tendon cells in culture. J Orthop Res 2005, 23:281-286.

42. de Mos M, van der Windt AE, Jahr H, van Schie HT, Weinans $H$, Verhaar JA, van Osch GJ: Can platelet-rich plasma enhance tendon repair? A cell culture study. Am J Sports Med 2008, 36:1171-1178.

43. Ni M, Tang P, Wang Y, Li G: [Experimental study on promoting bone consolidation by using platelet-rich plasma and decalcified bone matrix during distraction osteogenesis]. Zhongguo Xiu Fu Chong Jian Wai Ke Za Zhi 2011, 25:661-667.

44. Hammond JW, Hinton RY, Curl LA, Muriel JM, Lovering RM: Use of autologous platelet-rich plasma to treat muscle strain injuries. Am J Sports Med 2009, 37:1135-1142.

45. Sun Y, Feng Y, Zhang $C Q$, Chen $S B$, Cheng $X G$ : The regenerative effect of platelet-rich plasma on healing in large osteochondral defects. Int Orthop 2010, 34:589-597.

46. Schnabel LV, Mohammed HO, Miller BJ, McDermott WG, Jacobson MS, Santangelo KS, Fortier LA: Platelet rich plasma (PRP) enhances anabolic gene expression patterns in flexor digitorum superficialis tendons. J Orthop Res 2007, 25:230-240.

47. Lyras DN, Kazakos K, Verettas D, Polychronidis A, Tryfonidis M, Botaitis S, Agrogiannis G, Simopoulos C, Kokka A, Patsouris E: The influence of plateletrich plasma on angiogenesis during the early phase of tendon healing. Foot Ankle Int 2009, 30:1101-1106.

48. Lyras DN, Kazakos K, Verettas D, Botaitis S, Agrogiannis G, Kokka A, Pitiakoudis $M$, Kotzakaris A: The effect of platelet-rich plasma gel in the early phase of patellar tendon healing. Arch Orthop Trauma Surg 2009, 129:1577-1582.

49. Sheth U, Simunovic N, Klein G, Fu F, Einhorn TA, Schemitsch E, Ayeni OR, Bhandari M: Efficacy of autologous platelet-rich plasma use for orthopaedic indications: a meta-analysis. J Bone Joint Surg Am 2012, 94:298-307

50. Sánchez M, Anitua E, Azofra J, Andía I, Padilla S, Mujika I: Comparison of surgically repaired Achilles tendon tears using platelet-rich fibrin matrices. Am J Sports Med 2007, 35:245-251.

51. Schepull T, Kvist J, Norrman H, Trinks M, Berlin G, Aspenberg P: Autologous platelets have no effect on the healing of human achilles tendon ruptures: a randomized single-blind study. Am J Sports Med 2011, 39:38-47.

52. Filardo G, Presti ML, Kon E, Marcacci M: Nonoperative biological treatment approach for partial Achilles tendon lesion. Orthopedics 2010, 33:120-123.

53. Vogrin M, Rupreht M, Dinevski D, Hašpl M, Kuhta M, Jevsek M, Knežević $M$, Rožman P: Effects of a platelet gel on early graft revascularization after anterior cruciate ligament reconstruction: a prospective, randomized, double-blind, clinical trial. Eur Surg Res 2010, 45:77-85.

54. Vogrin M, Rupreht M, Crnjac A, Dinevski D, Krajnc Z, Recnik G: The effect of platelet-derived growth factors on knee stability after anterior cruciate ligament reconstruction: a prospective randomized clinical study. Wien Klin Wochenschr 2010, 122 Suppl 2:91-95.

55. Gardner MJ, Demetrakopoulos D, Klepchick PR, Mooar PA: The efficacy of autologous platelet gel in pain control and blood loss in total knee arthroplasty. An analysis of the haemoglobin, narcotic requirement and range of motion. Int Orthop 2007, 31:309-313.

56. Everts PA, Devilee RJ, Brown Mahoney C, Eeftinck-Schattenkerk M, Box HA,
Knape JT, van Zundert A: Platelet gel and fibrin sealant reduce allogeneic blood transfusions in total knee arthroplasty. Acta Anaesthesiol Scand 2006, 50:593-599.

57. Gosens T, Peerbooms JC, van Laar W, den Oudsten BL: Ongoing positive effect of platelet-rich plasma versus corticosteroid injection in lateral epicondylitis: a double-blind randomized controlled trial with 2-year follow-up. Am J Sports Med 2011, 39:1200-1208.

58. Hechtman KS, Uribe JW, Botto-vanDemden A, Kiebzak GM: Platelet-rich plasma injection reduces pain in patients with recalcitrant epicondylitis. Orthopedics 2011, 34:92.

59. Wang-Saegusa A, Cugat R, Ares O, Seijas R, Cuscó X, Garcia-Balletbó M: Infiltration of plasma rich in growth factors for osteoarthritis of the knee short-term effects on function and quality of life. Arch Orthop Trauma Surg 2011, 131:311-317.

60. Filardo G, Kon E, Buda R, Timoncini A, Di Martino A, Cenacchi A, Fornasari PM, Giannini S, Marcacci M: Platelet-rich plasma intra-articular knee injections for the treatment of degenerative cartilage lesions and osteoarthritis. Knee Surg Sports Traumatol Arthrosc 2010, 19:528-535.

61. Randelli P, Arrigoni P, Ragone V, Aliprandi A, Cabitza P: Platelet rich plasma in arthroscopic rotator cuff repair: a prospective RCT study, 2-year follow-up. J Shoulder Elbow Surg 2011, 20:518-528.

62. Castricini R, Longo UG, De Benedetto M, Panfoli N, Pirani P, Zini R, Maffulli N, Denaro V: Platelet-rich plasma augmentation for arthroscopic rotator cuff repair: a randomized controlled trial. Am J Sports Med 2011, 39:258-265.

63. Everts PA, Devilee RJ, Brown Mahoney C, van Erp A, Oosterbos CJ, Stellenboom M, Knape JT, van Zundert A: Exogenous application of platelet-leukocyte gel during open subacromial decompression contributes to improved patient outcome. A prospective randomized double-blind study. Eur Surg Res 2008, 40:203-210.

64. Everts PA, Knape JT, Weibrich G, Schönberger JP, Hoffmann J, Overdevest EP, Box HA, van Zundert A: Platelet-rich plasma and platelet gel: a review. J Extra Corpor Technol 2006, 38:174-187.

65. Anitua E, Orive G: Short implants in maxillae and mandibles: a retrospective study with 1 to 8 years of follow-up. J Periodontol 2010 81:819-826.

66. Anitua E, Orive G, Aguirre JJ, Ardanza B, Andía I: 5-year clinical experience with BTI dental implants: risk factors for implant failure. J Clin Periodontol 2008, 35:724-732.

67. Spero JA: Bovine thrombin-induced inhibitor of factor $V$ and bleeding risk in postoperative neurosurgical patients. Report of three cases. J Neurosurg 1993, 78:817-820.

68. Cmolik BL, Spero JA, Magovern GJ, Clark R: Redo cardiac surgery: late bleeding complications from topical thrombin-induced factor $\mathrm{V}$ deficiency. J Thorac Cardiovasc Surg 1993, 105:222-227; discussion 227-228.

69. Ortel TL, Mercer MC, Thames EH, Moore KD, Lawson JH: Immunologic impact and clinical outcomes after surgical exposure to bovine thrombin. Ann Surg 2001, 233:88-96

70. World Anti-Doping Agency: The World Anti-Doping Code. The 2010 Prohibited List. International Standard [http://www.wada-ama.org/ Documents/World_Anti-Doping_Program/WADP-Prohibited-list/ WADA_Prohibited_List_2010_EN.pdf]

71. World Anti-Doping Agency: The World Anti-Doping Code. The 2010 Prohibited List. International Standard [http://www.wada-ama.org/ Documents/World_Anti-Doping_Program/WADP-Prohibited-list/To_be_ effective/WADA_Prohibited_List_2011_EN.pdf]

72. Wright-Carpenter T, Klein P, Schäferhoff P, Appell HJ, Mir LM, Wehling P Treatment of muscle injuries by local administration of autologous conditioned serum: a pilot study on sportsmen with muscle strains. Int $\rfloor$ Sports Med 2004, 25:588-593.

73. Borselli C, Storrie H, Benesch-Lee F, Shvartsman D, Cezar C, Lichtman JW, Vandenburgh $\mathrm{HH}$, Mooney DJ: Functional muscle regeneration with combined delivery of angiogenesis and myogenesis factors. Proc Natl Acad SciUSA 2010, 107:3287-3292.

74. Daugherty K, Porucznik MA: Treating tendons, bones, and cartilage with PRP [http://www.aaos.org/news/aaosnow/jul11/cover2.asp]

75. Mishra A, Pavelko T: Treatment of chronic elbow tendinosis with buffered platelet-rich plasma. Am J Sports Med 2006, 34:1774-1778.

76. Porucznik MA: PRP an unproven option, agree forum experts [http://www. aaos.org/news/aaosnow/mar11/cover1.asp]

77. Eppley BL, Woodell JE, Higgins J: Platelet quantification and growth factor analysis from platelet-rich plasma: implications for wound healing. Plastic 
Reconstruct Surg 2004, 114:1502-1508.

78. Engebretsen L, Steffen K, Alsousou J, Anitua E, Bachl N, Devilee R, Everts P, Hamilton B, Huard J, Jenoure P, Kelberine F, Kon E, Maffulli N, Matheson G, Mei-Dan O, Menetrey J, Philippon M, Randelli P, Schamasch P, Schwellnus M, Vernec A, Verrall G: IOC consensus paper on the use of platelet-rich plasma in sports medicine. Br J Sports Med 2010, 44:1072-1081. doi:10.1186/ar3914

Cite this article as: Dhillon RS, et al.: Platelet-rich plasma therapy - future or trend? Arthritis Research \& Therapy 2012, 14:219. 